\title{
Reação de genótipos de nectarina (Prunus persica var. nucipersica) à ferrugem da folha, ao chumbinho e evolução da desfolha ${ }^{1}$
}

\author{
Reaction of genotypes of the nectarine (Prunus persica var. Nucipersica) to leaf rust \\ and shot hole, and the development of defoliation
}

\author{
Ricardo Antônio Ayub ${ }^{2 *}$, Marlon Assunção² e Adalci Leite Torres ${ }^{3}$
}

\begin{abstract}
RESUMO - A resistência genética às doenças é um progresso na produção de todas as culturas e fontes de resistência devem ser reportadas, auxiliando os programas de melhoramento. O presente trabalho objetivou avaliar a resistência de genótipos de nectarina à ferrugem da folha e ao chumbinho, assim como, correlacionar a intensidade das doenças com a desfolha prematura. Foram avaliados três genótipos de nectarina em delineamento de blocos ao acaso com dez repeticões. Com base nos resultados obtidos, o genótipo Bruna mostrou-se resistente ao chumbinho e suscetível à ferrugem, ao passo que o genótipo Sunripe foi resistente à ferrugem; FLA 9-15N foi moderadamente suscetível à ferrugem. Houve correlação apenas entre severidade da ferrugem e desfolha.
\end{abstract}

Palavras-chave: Nectarina. Plantas. Controle de doenças.

\begin{abstract}
Genetic resistance to disease can be seen as progress in the production of all crops, and sources of resistance have to be reported, thus helping improvement programs. This study aimed to evaluate the resistance of nectarine genotypes to leaf rust and shot hole, as well as to correlate the severity of the diseases with premature defoliation. Three genotypes of the nectarine were evaluated in a randomized block design with ten replications. Based on the results, the genotype Bruna proved resistant to shot hole and susceptible to leaf rust, while the genotype Sunripe was resistant to leaf rust. FLA $9-15 \mathrm{~N}$ was moderately susceptible to leaf rust. There was correlation between leaf-rust severity and defoliation only.
\end{abstract}

Key words: Nectarine. Plants. Disease Control.

\footnotetext{
*Autor para correspondência

${ }^{1}$ Recebido para publicação em 06/09/2011; aprovado em 05/11/2012

Parte do trabalho de pesquisa orientada do segundo autor apresentado ao Programa de Pós-Graduação em Agronomia da Universidade Estadual de Ponta Grossa, UEPG-PR

${ }^{2}$ Departamento de Fitotecnia e Fitossanidade, Universidade Estadual de Ponta Grossa/UEPG, Ponta Grossa-PR, Brasil, 84.030-900, rayub@uepg.br, marlon-assuncao@hotmail.com

${ }^{3}$ Universidade Estadual de Ponta Grossa/UEPG, Ponta Grossa-PR, Brasil, 84.030-900, adalcitorres@uepg.br
} 


\section{INTRODUÇÃO}

A Nectarina (Prunus persica var. nucipersica) é uma frutífera típica de clima temperado, origniária da China (NEVES; MANZIONE; VIEITES, 2002). Juntamente com o pêssego, a nectarina possui sua produção concentrada na região Sul. A área plantada no estado do Paraná está em torno de 1.600 hectares, produzindo cerca de 17.500 toneladas, com produtividade média de $11.000 \mathrm{~kg} \mathrm{ha}^{-1}$ (CITADIN, 2009).

O patógeno Tranzschelia discolor (Fuckel) Tranzschel \& Litv., causador da ferrugem da folha em nectarina, produz cinco diferentes tipos de esporos: uredinósporos, teliósporos, aeciósporos, picniósporos e basidiósporos, os quais são considerados um fator importante para a taxonomia deste fungo, com auxílio de microscopia eletrônica de varredura (MAY DE MIO; NOVAES; ALVES, 2006; REZENDE; DIANESE, 2003). Além destas características, este patógeno é heteróico, alternando dois hospedeiros durante o seu cliclo de vida, geralmente entre espécies de Prunus e espécies da família Ranunculaceae (ESTRADA et al., 2005). A associação de condições predisponentes para o desenvolvimento da doença com a falta de conhecimento das estratégias de manejo têm levado a grandes reduções na produção pela desfolha precoce (RODRIGUES et al., 2008). A incidência da ferrugem em pomares instalados com genótipos suscetíveis, também altera os processos fisiológicos da planta, causando floração no outono (CARVALHO et al., 2002).

Oagente etiológico do chumbinho, Wilsonomyces carpophilus (Lév.) Adaskaveg, pode causar sintomas nas folhas, flores, frutos e ramos. Dependendo das condições climáticas e da fase de desenvolvimento da cultura, a desfolha prematura poderá ocorrer, debilitando a planta (TEVIOTDALE; GOODELL; HARPEN, 2007).

De fato, a deficiência no conhecimento de estratégias de manejo eficientes agrava o cenário da fruticultura, no tocante ao cultivo de nectarina. Embora haja relatos do uso de algumas estratégias, tais como destruição de ramos e folhas infectadas e o uso de fungicidas, a resistência genética desempenha um papel de extrema importância no que tange às estratégias de manejo de ambas as doenças (LALANCETTE; MACFARLAND, 2007).

Este trabalho objetivou detectar fontes de resistência em três genótipos de nectarina à ferrugem da folha e ao chumbinho, assim como correlacionar a intensidade das doenças com a desfolha prematura.

\section{MATERIAL E MÉTODOS}

O experimento foi conduzido no município de Ponta Grossa, classificação climática $\mathrm{Cfb}$, no pomar do Departamento de Fitotecnia e Fitossanidade da UEPG, em delineamento de blocos casualizados com dez repetições. Os genótipos avaliados foram: Bruna, FLA 9-15N e Sunripe, plantados no ano de 2009. A condução foi realizada em "V", no espaçamento de 5,0 x 2,0 $\mathrm{m}$ e os tratos culturais permaneceram constantes, sendo estes, recomendados para a região.

As variáveis estudadas foram a incidência e a severidade da ferrugem e do chumbinho e evolução da desfolha. As amostras se constituíram de dez folhas coletadas em dois ramos mistos de um ano em lados opostos das árvores (MAY DE MIO; MOREIRA, 2003).

A incidência de ambas as doenças foi calculada pela porcentagem de folhas com sintomas em relação ao número total de folhas avaliadas (20 folhas) conforme a equação 1:

$\% I N C=\left(\frac{N^{o} \text { de folhas com sintomas }}{N^{o} \text { total de folhas }}\right)$

Para a avaliação da severidade da ferrugem no ramo foi utilizada uma escala diagramática desenvolvida por Martins (1994); com 10 níveis de severidade baseados na área foliar afetada, e para a avaliação de severidade do chumbinho a escala diagramática proposta por Challiol et al. (2006).

Os valores de incidência e severidade foram integrados pelo modelo trapezoidal (OLIVEIRA et al., 2007), calculando-se assim, o valor da área abaixo da curva de progresso da doença (AACPD) para a incidência (AACPI) e severidade (AACPS) de acordo com a seguinte equação 2 :

$\mathrm{AACPD}=\sum\left\{\left[\left(\mathrm{y}_{\mathrm{i}}+\mathrm{y}_{\mathrm{i}+1}\right) / 2\right] \times\left(\mathrm{t}_{\mathrm{i}+1}-\mathrm{t}_{\mathrm{i}}\right)\right\}$

onde, $\mathrm{y}_{\mathrm{i}}$ e $\mathrm{y}_{\mathrm{i}+1}$ - valores de duas leituras consecutivas da severidade, $\mathrm{e} ; \mathrm{t}_{\mathrm{i}}$ e $\mathrm{t}_{\mathrm{i}+1}$ - datas das duas leituras.

A desfolha foi calculada pela diferença do número de folhas observado entre cada avaliação.

Tanto os valores de incidência quanto os de severidade foram submetidos à análise de correlação de Pearson e submetidas ao teste $\mathrm{t}(\mathrm{P}<0,05)$, para verificação de significância das correlações.

Os dados obtidos foram computados e submetidos à análise de variância (ANAVA) e teste de comparação de médias (Tukey, $\mathrm{P}<0,05$ ), pelo software ESTAT versão 2.0 (UNESP - Jaboticabal). 


\section{RESULTADOS E DISCUSSÃO}

Foi possível verificar diferenças significativas dos três genótipos de nectarina testados com relação às variáveis epidemiológicas da ferrugem e do chumbinho e nos níveis médios de desfolha (Tabela 1).

Nota-se que não houve diferença significativa para a AACPS do chumbinho entre os genótipos Sunripe e FLA 9-15N, embora, ambos tenham sido significativamente mais suscetíveis que o genótipo Bruna para esta doença (Figura 1a).

Para os valores da AACPS da Ferrugem, o genótipo Bruna foi mais suscetível em relação ao Sunripe, não sendo estatisticamente diferente em relação à cultivar FLA 9-15N (Figura 1a).

Os valores da AACPI do chumbinho mostraram-se não significativos entre os genótipos Sunripe e FLA9 - 15N, muito embora, notou-se decréscimo significativo entre os genótipos Sunripe e Bruna (Figura 1b). Analisando-se o gráfico e comparando-se os dados da AACPI e AACPS, é possível verificar que os menores valores de AACPD para o chumbinho foram observados no genótipo Bruna (Figura 1a e 1b), sendo este genótipo, menos suscetível a esta doença.

Para os valores da AACPI da ferrugem, foi possível encontrar diferenças significativas entre as três cultivares, mostrando uma maior susceptibilidade nos genótipos FLA 9$15 \mathrm{Ne}$ Bruna (Figura 1b), sendo que para estas, também foram registrados os maiores valores de AACPS (Figura 1a). Os genótipos avaliados não apresentaram resistência completa, pois nenhum deles expressou reação do tipo imune.

Registraram-se valores elevados para a evolução da desfolha já na primeira leitura para os genótipos FLA 9 - 15N e Bruna (Figura 2a), evoluindo para um cenário mais grave

Tabela 1 - Resumo da análise de variância das variáveis epidemiológicas para Ferrugem e Chumbinho e níveis médios de desfolha em diferentes genótipos de nectarina (Prunus persica var. nucipersica)

\begin{tabular}{|c|c|c|c|c|c|c|}
\hline \multirow{3}{*}{ F V } & \multirow{3}{*}{ G L } & \multicolumn{5}{|c|}{ Teste F } \\
\hline & & \multicolumn{2}{|c|}{---------------Ferrugem-------------- } & \multicolumn{2}{|c|}{-------------Chumbinho--------------- } & \multirow[t]{2}{*}{ Desfolha } \\
\hline & & AACPS & AACPDI & AACPS & AACPI & \\
\hline Blocos & 9 & $0,66^{\mathrm{ns}}$ & $1,51^{\mathrm{ns}}$ & $2,29^{\mathrm{ns}}$ & $2,72 *$ & $1,14^{\mathrm{ns}}$ \\
\hline Genótipos & 2 & $9,65 * *$ & $30,38 * *$ & $6,64 * *$ & $5,30 *$ & $7,56 * *$ \\
\hline Resíduo & 18 & - & - & - & - & - \\
\hline
\end{tabular}

F.V - Fontes de variação; G L - Graus de liberdade; AACPS - Área Abaixo da Curva de Progresso da Severidade; AAPI - Área baixo da curva de Progresso da Incidência; ${ }^{n}$ - não significativo; * - significativo ao nível de $5 \%$ de pelo teste $\mathrm{F}$; ** - significativo ao nível $1 \%$ pelo teste $\mathrm{F}$

Figura 1 - Valores da Área Abaixo da Curva de Progresso da Severidade e Incidência da Ferrugem e do Chumbinho em três genótipos de nectarina (Prunus persica var. nucipersica). Médias seguidas das mesmas letras minúsculas entre os genótipos não diferem estatísticamente (Tukey, $\mathrm{P}<0,05)$ para Chumbinho. Médias seguidas das mesmas letras maiúsculas entre os genótipos não diferem estatísticamente (Tukey, $\mathrm{P}<0,05)$ para Ferrugem. Barras correspondem ao erro padrão da média
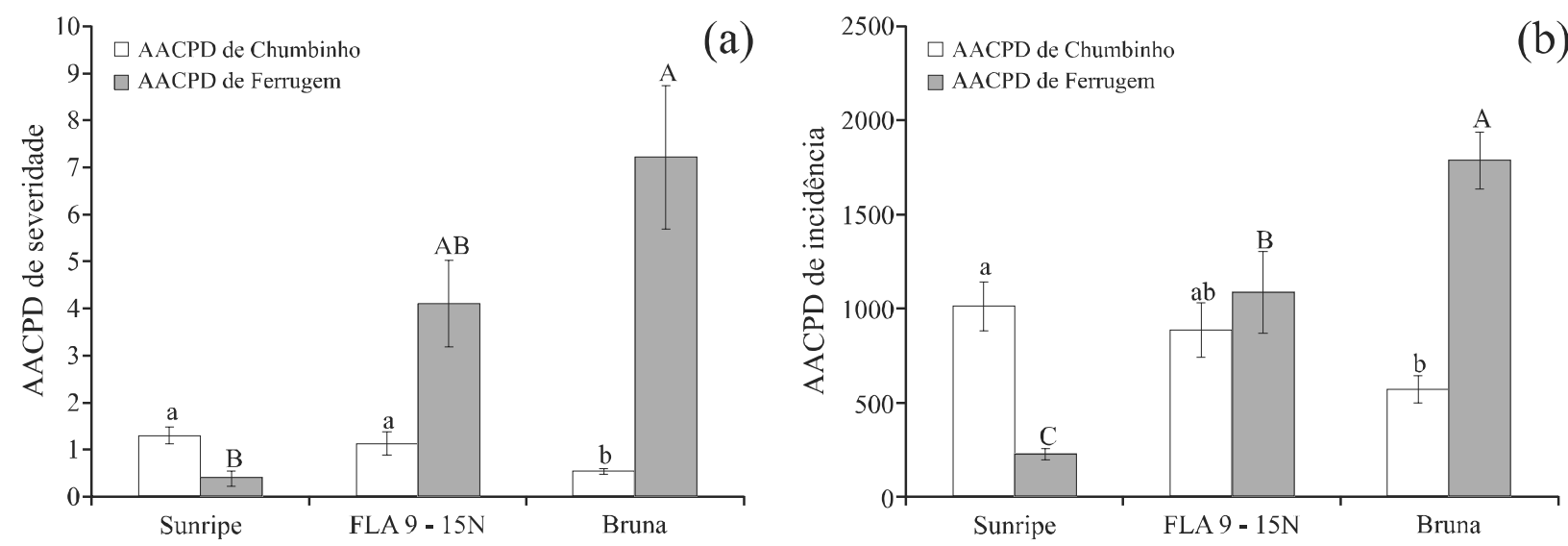
Figura 2 - (a) Evolução da desfolha de genótipos de nectarina (Prunus pérsica var. nucipersica). Barras correspondem ao erro padrão da média. (b) Desfolha média dos genótipos. Médias seguidas das mesmas letras minúsculas entre os genótipos não diferem estatísticamente (Tukey, $p<0,05$ ). Barras correspondem ao erro padrão da média

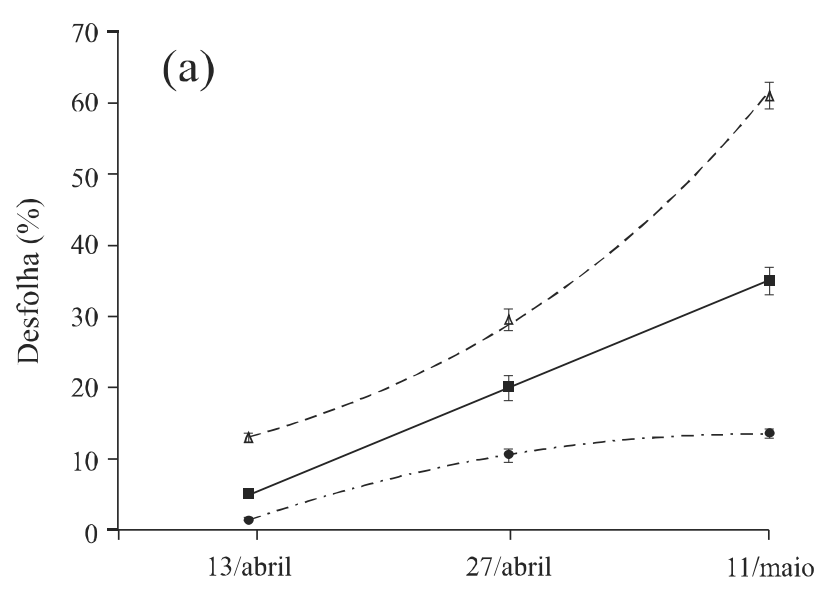

em torno de 35 e $60 \%$, respectivamente. Como esperado, houve uma evolução mais lenta e menores níveis de desfolha verificados no genótipo Sunripe, que apresentou baixos valores acumulados de AACPD de Ferrugem, tanto para incidência quanto severidade, assim como, mostraramse significativos os níveis de desfolha entre os genótipos (Figura 2b), sendo FLA 9-15N e Bruna mais suscetíveis à desfolha em relação ao genótipo Sunripe.

Estudos realizados por Estrada e Adaskaveg (2003), Souza et al. (2007), Alves e May De Mio (2008) relataram que a desfolha prematura induz a planta a florescer no outono. Alves e May De Mio (2008) também reportaram o efeito negativo da desfolha sobre a profundidade da dormência das gemas, assim, reduzindo o número de flores abertas na época da floração.

Essa brotação estimulada que é perdida em meses posteriores pela desfolha natural, consome as reservas de carboidratos necessárias para a retomada fisiológica da planta após sair da dormência (CITADIN et al., 2005). Este desperdício de energia resultará na redução da produtividade em colheitas posteriores (ESTRADA et al.; 2003). Alves (2006) reportou que os níveis totais de carboidratos solúveis em ramos diminuem à medida que a desfolha aumenta. Para tanto, há a necessidade de ser mantida a retenção foliar até o período de desfolha natural para concentrar as reservas de carboidratos nos ramos.

A ferrugem é uma das doenças responsáveis pela desfolha prematura em pessegueiro e nectarina, podendo comprometer a produtividade futura (BLEICHER, 1997). Challiol et al. (2006), avaliando escalas diagramáticas

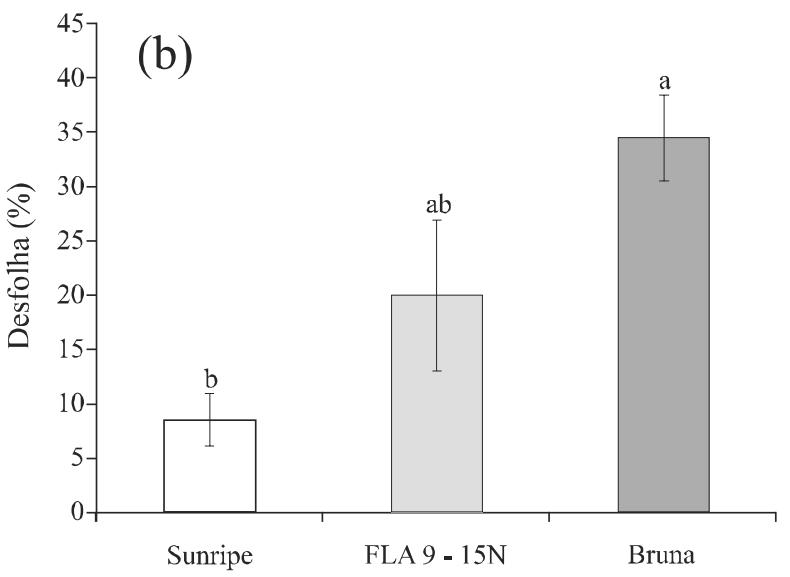

em dois sistemas de produção de pessegueiro, verificaram que a desfolha é acompanhada de elevados níveis de severidade. Este fato pode ser visualizado pelas análises de correlação (Tabela 2). Observou-se que a desfolha foi positivamente correlacionada somente com a severidade, explicando 99,55\% da variação da desfolha dos genótipos (Figura 3). Apesar de Assman et al. (2010), reportarem correlações positivas entre severidade de ferrugem e desfolha $(\mathrm{R}=0,79 * *)$, os mesmos também reportaram correlação positiva entre desfolha e incidência $\left(\mathrm{R}=0,59^{* *}\right)$. No entanto, é temoroso assumir que a incidência é uma variável epidemiológica adequada para distinguir níveis de resistência se esta possui correlação com a desfolha, como mostram Assman et al. (2010), pois a incidência não reflete a severidade da doença (incidência $x$ severidade, $R=0,9947^{\text {ns }}$, Tabela 1) em condições onde podem haver diferenças varietais significativas. Em outras palavras, para a ferrugem, fica difícil distinguir os níveis de resistência apenas com base na incidência, pois pode haver níveis

Tabela 2 - Análise da correlação de Pearson entre severidade/ desfolha, incidência/desfolha e incidência/severidade para ferrugem

\begin{tabular}{lcc}
\hline \multicolumn{1}{c}{ Análise } & $\mathrm{R}$ & $\mathrm{t}$ \\
\hline Severidade x desfolha & 0,9977 & $14,879^{*}$ \\
Incidência x desfolha & 0,9855 & $5,818^{\mathrm{ns}}$ \\
Incidência x severidade & 0,9947 & $9,660^{\mathrm{ns}}$
\end{tabular}

$\mathrm{R}$ - Correlação de Pearson; $\mathrm{t}$ - t-Student calculado; *Significativo ao nível $5 \%$ de pelo teste t-Student $(t=12,706) ;{ }^{\text {ns }}=$ não significativo 
Figura 3 - Regressão da desfolha e severidade para ferrugem da folha

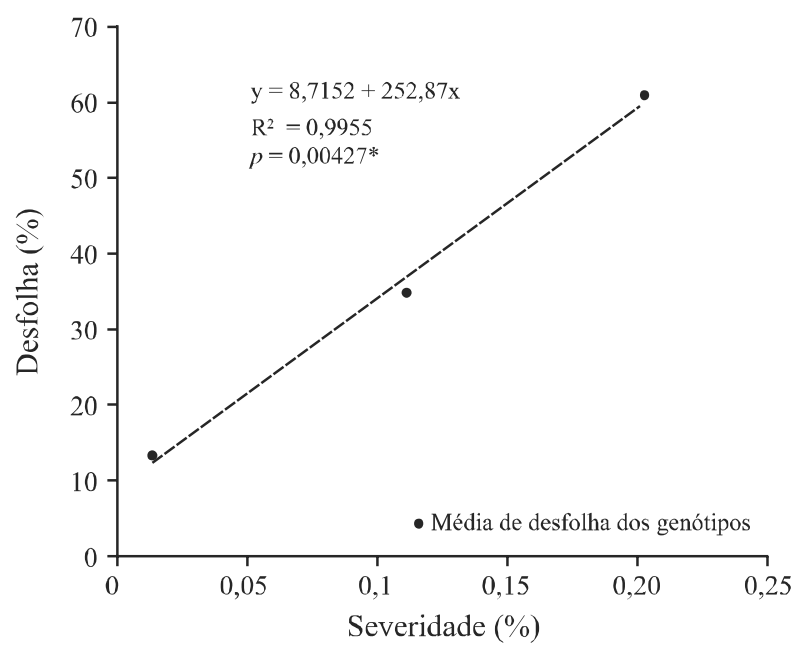

* Significativo ao nível de $5 \%$

máximos de incidência, porém, intensidades diferentes entre os genótipos.

Carvalho et al. (2002) relatam que, apesar da incidência ser largamente utilizada como uma variável de quantificação de doenças, é a severidade que está mais correlacionada com a queda de produção.

Para Amorim (1995), a quantificação de danos usando a incidência só pode ser utilizada em casos de doenças sistêmicas, como viroses e murchas vasculares, o que não condiz no caso de ferrugem, pois se trata de uma doença não sistêmica.

Não houve correlação entre as varáveis epidemiológicas do chumbinho e da desfolha.

\section{CONCLUSÕES}

1.O genótipo Bruna foi mais resistente ao chumbinho, em relação às cultivares FLA 9 - 15N e Sunripe;

2.O genótipo Sunripe foi mais resistente à Ferrugem, quando comparado aos genótipos FLA $9-15 \mathrm{~N}$ e Bruna, resultando assim, em baixos níveis de desfolha;

3.FLA $9-15 \mathrm{~N}$ foi moderadamente suscetível à ferrugem da folha;

4.Com base na análise de correlação, apenas a severidade da ferrugem contribui para a desfolha prematura, sendo esta a variável epidemiológica que melhor responde à diferenciação de níveis varietais.

\section{REFERÊNCIAS}

ALVES, G. Avaliação de danos causados pela ferrugem em pomar de pessegueiro da cultivar chimarrita. 2006. $71 \mathrm{f}$. Dissertação (Mestrado em Ciências) - Universidade Federal do Paraná. Curitiba. 2006.

ALVES, G.; MAY DE MIO, L. L. Efeito da desfolha causada pela ferrugem na floração e produtividade do pessegueiro. Revista Brasileira de Fruticultura, v. 30, n. 4, p. 907-912, 2008.

AMORIM, L. Avaliação de doenças. In: BERGAMIM FILHO, A.; KIMATI, H.; AMORIM, L. (Ed.). Manual de fitopatologia: princípios e conceitos. 3.ed. São Paulo: Agronômica Ceres, 1995. v. 01, p. 649-670.

ASSMAN, A. P. et al. Reação de genótipos de pessegueiro à ferrugem-da-folha. Pesquisa Agropecuária Brasileira, v. 45, n. 1, p. 32-40, 2010.

BLEICHER, J. Doenças de rosáceas de caroço. In: KIMATI, H. et al. Manual de fitopatologia: Doenças das plantas cultivadas. 3. ed. São Paulo: Agronômica Ceres, 1997. v. 02, p. 577-583.

CAMARGO, L. E. A.; BERGAMIM FILHO, A. Controle genético. In: BERGAMIM FILHO, A.; KIMATI, H.; AMORIM, L. (Ed.). Manual de fitopatologia: princípios e conceitos. 3.ed. São Paulo: Agronômica Ceres, 1995. v. 01, p. 729-760.

CARVALHO, V. L. et al. Alternativas de controle da ferrugem do pessegueiro Tranzschelia discolor (fuckel) tranzschel litivinov. Ciência Agrotécnica, v. 26, n. 2, p. 227-231, 2002.

CHALLIOL, M. A. et al. Elaboração de escala diagramática para furo-de-bala e avaliação de doenças foliares em dois sistemas de produção de pessegueiro. Revista Brasileira de Fruticultura, v. 28, n. 3, p. 391-396, 2006.

CITADIN, I. et al. Controle de ferrugem da folha de pessegueiro mediante pulverizações com diferentes fungicidas. Revista Brasileira de Fruticultura, v. 27, n. 2, p. 317-319, 2005.

CITADIN, I. Fruteiras de caroço. In: ENCONTRO DE FRUTICULTURA DOS CAMPOS GERAIS, 2, 2009. Ponta Grossa. Anais... Ponta Grossa: UEPG, 2009.

ESTRADA, A. S. et al. New fungicides and application strategies based on inoculum and precipitation for managing stone fruit rust on peach in California. Plant Disease, v. 87, n. 9, p. 1094-1101, 2003.

ESTRADA, A. S. et al. Initial infection and colonization of leaves and stems of cling peach by Tranzschelia discolor. Phytopathology, v. 95, n. 8, p. 942-950, 2005.

ESTRADA, A. S.; ADASKAVEG, J. Temporal and quantitative analyses of stem lesion development and foliar disease progression of peach rust in California. Phytopathology, v. 94, n. 1, p. 52-60, 2003.

LALANCETTE, N.; MACFARLAND, K. A. Phytotoxicity of copper-based bactericides to peach and nectarine. Plant Disease, v. 91, n. 9, p. 1122-1130, 2007.

MARTINS, M. C. Quantificação dos parâmetros monocíclicos e controle químico da ferrugem do 
pessegueiro. 1994. 68 f. Dissertação (Mestrado em Agronomia - Fitopatologia) - Escola Superior de Agricultura "Luiz de Queiroz", Universidade de São Paulo. Piracicaba. 1994.

MAY DE MIO, L. L.; NOVAES, Q. S.; ALVES, E. Metodologias de preparação de amostras de ferrugem para estudos morfológicos de urediniósporos por meio de microscopia eletrônica de varredura. Summa Phytopathologica, v. 32, n. 3, p. 267-273, 2006 .

MAY DE MIO, L. L.; MOREIRA, L. M. Avaliação de doenças em fruteiras de caroço. Curitiba: Secretaria de Estado da Agricultura e do Abastecimento, 2003. 15 p. (Informativo Técnico).

NEVES, L. C.; MANZIONE, R. L.; VIEITES, R. L. Radiação gama na conservação pós-colheita da nectarina (Prunus persica var. nucipersica) frigoconservada. Revista Brasileira de Fruticultura, v. 24, n. 3, p. 676-679, 2002.
OLIVEIRA, A. R. et al. Fungicidas, doses e volumes de calda no controle químico da ferrugem da folha em aveia. Engenharia Agrícola, v. 27, p. 48-55, 2007.

REZENDE, D. V.; DIANSESE, J. C. Revisão taxonômica de algumas espécies de ravenelia em leguminosas do cerrado brasileiro. Fitopatologia Brasileira, v. 28, n. 1, p. 27-36, 2003.

RODRIGUES, A. R. et al. Intensidade de poda verde em pessegueiro para controle da ferrugem Tranzschelia discolor (fuckel) tranzschel e litvinov. Revista Brasileira de Fruticultura, v. 30, n. 3, p. 634-638, 2008.

SOUZA, S. R. et al. Doenças foliares, cancro e número de frutos relacionados com a adubação nitrogenada em pessegueiro. Revista Brasileira de Fruticultura, v. 29, n. 2, p. 260-264, 2007.

TEViOTDALE, B. L.; GOODELL, N.; HARPER. D. Abscission and kernel quality of almond fruit inoculated with the shot hole pathogen Wilsonomyces carpophilus. Plant Disease, v. 81, n. 12, p. 1454-1458, 2007. 